\title{
Anteroposterior lumbar spine X-ray of L5 lamina for screening of possibility of lower lumbar disc herniation in young adults
}

\section{Lin Jin}

Hebei Medical University Third Affiliated Hospital

\section{Li Zhang}

Hebei Medical University Third Affiliated Hospital

Jialiang Guo

Hebei Medical University Third Affiliated Hospital

\section{Ruipeng Zhang}

Hebei Medical University Third Affiliated Hospital

\section{Yingchao Yin}

Hebei Medical University Third Affiliated Hospital

\section{Zhiyong Hou ( $\nabla$ drzyhou@gmail.com )}

Hebei Medical University Third Affiliated Hospital https://orcid.org/0000-0001-5838-4025

\section{Yingze Zhang}

Hebei Medical University Third Affiliated Hospital

\section{Research article}

Keywords: Spine, Lumbar disc herniation, Lumbar lamina, X-ray, Young adults

Posted Date: December 1st, 2020

DOl: https://doi.org/10.21203/rs.3.rs-114591/v1

License: (c) (i) This work is licensed under a Creative Commons Attribution 4.0 International License. Read Full License 


\section{Abstract}

Background: Plain radiographs are rarely used in the imaging evaluation of lumbar disc herniation (LDH). The L5 lamina is the important skeletal structure at the back of the lower lumbar vertebra. This study investigated the association between the height of L5 lamina under anteroposterior lumbar spine X-ray and lower LDH, to determine its significance to the onset of LDH in young adults.

Methods: We conducted a retrospective study of 160 patients aged 18 to 39 years with lower LDH and 160 healthy controls. The anteroposterior lumbar spine X-ray was used to image features of the L5 lamina. The height of L5 lamina (" $h$ ") and of the space between L4 and S1 lamina ("H") were measured. The difference in height of L5 lamina in each study group was assessed as the ratio of " $\mathrm{h} / \mathrm{H}$ ".

Results: There was no significant difference in sex, age, occupation type, body mass index (BMI), family history or smoking status $(p>0.05)$ between LDH group and the control group. The mean ratio $(95 \% \mathrm{Cl})$ of "h/H" in LDH and control group was $0.28(0.26,0.31)$ and $0.35(0.32,0.38)$ respectively, with statistical difference $(p<0.05)$. The diagnostic accuracy of " $\mathrm{h} / \mathrm{H}$ " ratio was investigated using the receiver operating characteristic (ROC) curve. The area under the curve was 0.835 (95\% $\mathrm{Cl} 0.789,0.881)$, using a cut-off of 0.315 (sensitivity 0.806 , specificity 0.794$)$. A decrease in the " $h / H$ " ratio, showed an increasing linear trend in the protrusion proportion of $L 4 / 5$ segments $(Z=5.943, p<0.05)$.

Conclusions: Young adults with developmental defects of L5 lamina are more likely to develop lower $\mathrm{LDH}$. Assessment of " $\mathrm{h} / \mathrm{H}$ " ratio could be used for screening or prediction of asymptomatic or mildly symptomatic lower LDH in young adults.

\section{Background}

Lumbar disc herniation (LDH) is a common degenerative disease among the elderly with reported incidence of about $2 \%-5 \%[1,2]$. Although rare in young adults, the change to more sedentary lifestyle in the recent years has led to increased prevalence of LDH in this group [3, 4]. This has resulted in increased financial burden to family and social health care $[5,6]$.

Patients with herniated disc segments at L4/5 and/or L5/S1 account for more than $90 \%$ of all LDH patients [7]. LDH of elderly patients is often caused by degeneration of bone and disc, while mechanical changes of spine caused by congenital or acquired factors is often the cause of LDH in young adults. Previous studies have investigated the relationship between abnormalities of lumbosacral skeletal structure and LDH [8-10]. Asano et al. [11] showed that the posterior structure of the vertebral body was subjected to $24-30 \%$ pressure, $21-26 \%$ tension and $42-54 \%$ rotation stress. The $L 5$ lamina is an important skeletal structure at the back of the lower lumbar vertebra, and its hypoplasia leads to poor stability of the lower lumbar spine. This causes the center of human gravity to move to the intervertebral disc of $L 4 / 5$ and $L 5 / S 1$, which may accelerate degeneration of these discs. 
Magnetic resonance imaging (MRI) is a medical imaging technology that is commonly used to evaluate patients with symptomatic spinal complications and to locate prominent segments of the spine $[12,13]$. But its disadvantage is that the equipment is expensive, which makes it impossible to popularize in primary hospitals. Our previous research has demonstrated that the L5 lamina in young adults with lower LDH was less in height than older patients [14]. An X-ray assessment of the L5 lamina height can potentially be used as an effective and affordable test to diagnose or predict lower LDH in young adults. This study aimed to investigate the association between height of the L5 lamina under anteroposterior lumbar spine X-ray and onset of lower LDH in young adults.

\section{Methods}

Ethical approval for the study was provided by the institutional ethics committee. From January 2019 to January 2020, 160 cases aged 18-39 years, diagnosed with definite lower LDH (L4/5 or L5/S1) by computed tomography (CT) or MRI of the lumbar intervertebral disc were enrolled into this retrospective study. Additionally, 160 individuals (18-39 years old) with no LDH were enrolled as controls. The controls were selected from patients who underwent anteroposterior lumbar spine X-rays for reasons other than lower back pain or LDH. Due to this was a retrospective study and all patients' information anonymized, the patient informed consent was waived.

Participants were excluded if they presented with vertebral fractures, severe spinal traumatic history, had a previous lumbar operation, spinal tumors, severe lumbosacral vertebra deformity (including lumbosacral transitional vertebra, complicated scoliosis, spondylolisthesis, spina bifida) or any other symptomatic lumbosacral vertebra disease.

\section{Imaging And Measurement Techniques}

All study participants were imaged using the standard anteroposterior lumbar spine X-ray in the supine position, to avoid measurement error caused by different X-ray beam direction. The picture archive and communication system (PACS) was then used to measure vertical height of the superior and inferior edges of the L5 lamina abutting the spinous process as " $h$ ". The vertical height from the inferior edge of the L4 lamina to the superior edge of the $\mathrm{S} 1$ laminae, denoted as " $\mathrm{H}$ " was also measured. The lengths of " $h$ " and " $H$ " were measured and we calculated the ratio of " $h / H$ " to indirectly evaluate the height of the L5 lamina in its upper and lower segments (Fig. 1). All measurements were performed by an independent radiologist who was unaware of the research objectives.

\section{Statistical Analysis}

The baseline characteristics of study participants including age, sex, type of occupation, level of physical activity, body mass index (BMI), smoking history, and family history of LDH were collected. Data analysis was performed using SPSS version 21.0. The assumption of normal distribution of continuous variables was tested using the Kolmogorov-Smirnov. Continuous variables were presented as mean \pm SD or median, while categorical variables were expressed as frequency and percentages. Group comparisons 
were appropriately performed using the chi-square test, Student's $t$ test or Mann-Whitney $U$ test. The association between the ratio of "h/H" and the onset of lower $\mathrm{LDH}$ was analysed using the receiver operating characteristic (ROC) curve. In the LDH group, we analyzed the relationship between the "h / $\mathrm{H}$ "

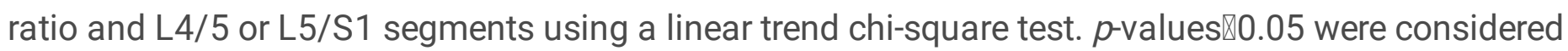
statistically significant.

\section{Results}

In total, 160 patients with lower LDH and 160 healthy controls were included in the study. Table 1 shows the distribution of baseline characteristics of study participants. There was no statistically significant difference between patients with lower LDH and controls in sex, age, occupation type, BMI, family history or smoking status $(p>0.05)$. The mean ratio of " $h / H$ " in the LDH group $0.28(0.26,0.31)$ was significantly lower than that in the control group $0.35(0.32,0.38)(p<0.05)$. The ROC curve analysis with cut-off value for the ratio of " $h / H$ " was 0.315 (sensitivity 0.806 , specificity 0.794 ), showed the area under the curve was $0.835(0.789,0.881)$ (Fig. 2).

Table 1

The demographics in both the LDH group and control group

\begin{tabular}{|llll|}
\hline & LDH(n=160) & Control $(n=160)$ & $p$ value \\
\hline Age (years) & $30(24,34)$ & $30(24,35)$ & $0.982^{\mathrm{a}}$ \\
\hline Sex (n) & & & $0.053^{\mathrm{b}}$ \\
Male & 103 & 86 & \\
\hline Female & 57 & 74 & $0.143^{\mathrm{c}}$ \\
BMI & $24.33 \pm 2.68$ & $23.90 \pm 2.53$ & $0.276^{\mathrm{b}}$ \\
\hline Smoker (n) & 20 & 14 & $0.627^{\mathrm{b}}$ \\
\hline Family history (n) & 10 & 8 & $0.754^{\mathrm{b}}$ \\
\hline Manual laborer (n) & 25 & 23 & $0.000^{\mathrm{a}}$ \\
\hline Ratio(h/H) & $0.28(0.26,0.31)$ & $0.35(0.32,0.38)$ & \\
\hline a Student's t-test & & & \\
\hline b Chi-square test & & & \\
\hline c Mann-Whitney U test & & & \\
\hline
\end{tabular}


Further, patients in the LDH group were divided into 5 groups based on the "h/H" ratio, to analyze the relationship between the " $\mathrm{h} / \mathrm{H}$ " ratio and $\mathrm{L} 4 / 5$ or $\mathrm{L} 5 / \mathrm{S} 1$; group $\mathrm{A}(<0.25, \mathrm{n}=22)$, group $\mathrm{B}(0.25-0.28, \mathrm{n}=$ 68), group $C(0.29-0.32, n=42)$, group $D(0.33-0.36, n=16)$, and group $E(>0.36, n=12)$ (Table 2$)$. The linear chi-square trend test showed that there was a linear trend between the ratio of salient segments and the " $\mathrm{h} / \mathrm{H}$ " ratio $(\mathrm{Z}=5.943, p=0.015)$. The results show a linear increasing trend in the protrusion proportion of $L 4 / 5$ segments, with a decrease in the " $h / H$ " ratio.

Table 2

The relationship between the "h $/ \mathrm{H}$ " ratio and $\mathrm{L} 4 / 5$ or $\mathrm{L} 5 / \mathrm{S} 1$ segments

\begin{tabular}{|c|c|c|c|c|c|}
\hline & $h / H$ & $\mathrm{n}$ & L4/5(\%) & L5/S1(\%) & $p$ value \\
\hline$A$ & $\otimes 0.25$ & 22 & $14(64 \%)$ & $8(36 \%)$ & \multirow[t]{5}{*}{$0.015^{\star}$} \\
\hline B & $0.25-0.28$ & 68 & $34(50 \%)$ & $34(50 \%)$ & \\
\hline C & $0.29-0.32$ & 42 & $17(40 \%)$ & $25(60 \%)$ & \\
\hline D & $0.33-0.36$ & 16 & $6(38 \%)$ & $10(63 \%)$ & \\
\hline E & 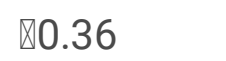 & 12 & $3(25 \%)$ & $9(75 \%)$ & \\
\hline \multicolumn{5}{|c|}{${ }^{*} p \bowtie 0.05$} & \\
\hline
\end{tabular}

\section{Discussion}

LDH is a commonly regarded as a high-risk degenerative disease of the elderly. The current sedentary and physically inactive lifestyle of many young adults, leads to long-term excessive pressure on the waist, which causes chronic lumbar muscle strain. Over time, structural variation in the lumbosacral vertebrae and pathological changes in the lumbar disc, can result in the occurrence of LDH. Previous epidemiological studies have found that sex, age, BMI, smoking, occupation type and level of physical activity are the main risk factors for lumbar disc degeneration and herniation [15]. Nevertheless, a study on twins indicated that genetic sources exist in over $70 \%$ of patients with LDH [16]. The study found that compared to acquired environmental factors, congenital or developmental factors may be more critical in the occurrence and development of LDH.

The developmental difference of lumbosacral bone structure has an important effect on its stability. The posterior longitudinal ligament divides the spine into anterior and posterior parts. Previous research has reported that the anterior structure of the lumbar spine mainly bears the compression load and absorbs the shock generated by the spine, while the posterior structure mainly controls the complex activities of different types of lumbar vertebrae, such as flexion and extension, lateral bending, and rotation [17]. However, King and Yang et al. $[18,19]$ reported that the lumbar posterior structure also has statics 
function that cannot be ignored, but that the compression load it bears varies greatly with different postures.

Lumbar lamina is the skeletal structure in the posterior part of lumbar vertebrae. Its integrity plays a vital role in maintaining the stability of lumbosacral vertebrae. Biomechanical experimental studies have analyzed the function of the lumbar lamina and shown that laminectomy reduced torsion moment to failure and torsion stiffness by approximately $18 \%$ in lumbar vertebrae [20]. In addition, the strength was reduced by $44.2 \%$ and the stiffness was reduced by $19.9 \%$ when shear loading [21, 22]. Raj D. Rao et al. reported that laminectomy caused more instability of motion segment of the spine compared to laminotomy and increased the stress to the anterior intervertebral disc annulus [23]. Cunningham et al. [24] also reported in their study that the pressure in the nucleus pulposus will increase significantly after complete instability of rear structure (including partial laminectomy). Pressure changes in the intervertebral disc can result in altered metabolism and apoptosis of cells, leading to long-term disc degeneration [25-27]. Consequently, lumbar posterior instability causes weight-bearing transfer from the posterior component to the anterior component, which may increase the risk of LDH. The most prominent segment of LDH is L4/L5 and/or L5/S1. The L5 lamina is the important skeletal structure at the back of the lower lumbar vertebra. Unlike laminectomy, our objective was to investigate a congenital or developmental defect or weakness in the L5 lamina, thus increasing the possibility of lower LDH, which was supported by our results.

Lamina horizontalization is considered to be one of the causes of the lumbar sagittal instability. [28] Lamina horizontalization can be manifested as a decrease in the height of the lamina under the anteroposterior lumbar spine X-ray. This is consistent with our conclusion and can be used as a special form of lamina height reduction. Spina bifida occulta (SBO) is a common deformity in the lumbosacral region, where the lamina of one or more vertebrae is not completely closed. The vast majority of individuals with SBO remain asymptomatic for life and the incidence of SBO varies from $0.6-25 \%$ [29, 30]. A study by Avrahami et al. [31] reported a higher prevalence of LDH among SBO patients, which was shown to increase with age. SBO patients have defects in the posterior lumbosacral vertebrae that leads decreased spinal stability, and increases the risk of posterior disc herniation, which supported our conclusions. However, the difference in the current study is that the L5 laminae in the LDH group had a developmental defect rather than reaching the degree of failed fusion.

Appropriate control is essential for clinical trials. Compared to our previous study [14], the control group enrolled young cases without LDH and low back pain, which can be more precisely reflecting the influence of the height of L5 lamina on the onset of lower LDH. Regarding the risk factors associated with LDH, numerous studies have investigated the effect of sex, BMI, physical labor intensity, smoking history, and family history $[15,32-36]$. In the present study, we excluded the confounding factors, such as sex, BMI, smoking, etc. In addition to skeletal structures, spinal ligaments are important in stabilizing intervertebral discs [37]. When selecting participants for enrollment, we used MRI to exclude any adverse conditions of ligament damage and calcification, to ensure the integrity and strength of the lumbosacral ligament. 
Plain radiographs are rarely used in the diagnosis of LDH as MRI or CT are the preferred methods [13]. Our study provides orthopedic surgeons with a simpler and more affordable imaging technique that can be used to predict the risk of lower LDH in asymptomatic young adults. We applied ROC curve analysis to predict the onset risk of lower $\mathrm{LDH}$, where the cutoff value of the " $\mathrm{h} / \mathrm{H}$ " ratio was 0.315 . Based on this, patients with " $\mathrm{h} / \mathrm{H}$ " ratio less than 0.315 , were more likely to suffer from lower $\mathrm{LDH}$. Our results show that, as the proportion of " $\mathrm{h} / \mathrm{H}$ " decreased, the protrusion segment tended to be $\mathrm{L} 4 / 5$. We determined that was related to the physiological lordosis of the lumbosacral vertebra and the characteristics of upright walking. Lumbar posterior instability causes weight-bearing transfer from the posterior component to the anterior component, so the $L 4 / 5$ intervertebral disc, which is more affected by the vertical load, can accelerate degeneration more easily. Additionally, the iliac lumbar ligament mainly arises from the L5 transverse process, which can stabilize the lumbosacral union and thus reduce the impact of lumbar posterior instability on this segment [38].

Several limitations should be considered in interpreting the results of this study. The study had a relatively small number of participants, who were selected from a single hospital. Additionally, anatomical differences in the lumbosacral vertebra may vary among different ethnicities, the population of this study is from northern China. The anteroposterior lumbar spine X-ray used for imaging, was restricted to the coronal plane of the L5 lamina, limiting analysis of its three-dimensional shape. Further studies on the three-dimensional reconstruction and mechanical analysis of L5 lamina should be conducted, to accurately reflect the effect of L5 lamina height on the degeneration of lumbosacral vertebrae.

\section{Conclusions}

The developmental difference in the height of L5 lamina is an important factor affecting the disc herniation of its upper and lower segments. The ratio of the height of L5 lamina to the height of upper and lower lamina space determined by standard anteroposterior lumbar spine X-rays can be used to screen lower LDH in young adults. This simple imaging technique can be used to evaluate asymptomatic or mildly symptomatic individuals to help promote changes in daily life and work habits of high-risk individuals, thereby avoiding or delaying the onset of LDH.

\section{Abbreviations}

LDH: Lumbar disc herniation; MRI: Magnetic resonance imaging; CT: Computed tomography; BMI: Body mass index; ROC: Receiver operating characteristic; SBO: Spina bifida occulta

\section{Declarations}

\section{Acknowledgements}

Nil. 


\section{Authors' contributions}

All authors participated in the design of the study, data collection, statistical analysis and help with the writing and final approved of the manuscript.

\section{Funding}

Youth Science and Technology Project of Hebei Provincial Health Commission (Grant no. 20180425).

\section{Availability of data and materials}

The data used to support the findings of this study are included within the article and are available from the corresponding author upon reasonable request.

\section{Competing interests}

On behalf of all authors, the corresponding author states that there is no conflict of interests.

\section{Ethics approval and consent to participate}

Ethical approval for the study was provided by the Ethics Committee of Third Hospital of Hebei Medical University. Due to this was a retrospective study and all patients' information anonymized, the patient informed consent was waived.

\section{Competing interests}

On behalf of all authors, the corresponding author states that there is no conflict of interests.

\section{Author details}

${ }^{1}$ Department of Orthopaedic Surgery, Third Hospital of Hebei Medical University, Shijiazhuang, Hebei, 050051, China. ${ }^{2}$ Key laboratory of biomechanics of Hebei Province, Shijiazhuang, Hebei, 050051, China.

${ }^{3}$ Chinese Academy of Engineering, Beijing 100088, China.

\section{References}

1. Younes M, Béjia I, Aguir Z, Letaief M, Hassen ZS, Touzi M, et al. Prevalence and risk factors of diskrelated sciatica in an urban population in Tunisia. Joint Bone Spine. 2006;73(5):538-42.

2. Heliövaara M, Mäkelä M, Knekt P, Impivaara O, Aromaa A. Determinants of sciatica and low-back pain. Spine.1991;16(6):608-14.

3. Fei H, Li WS, Sun ZR, Ma QW, Chen ZQ. Analysis of Spino-pelvic Sagittal Alignment in Young Chinese Patients With Lumbar Disc Herniation. Orthop Surg. 2017;9(3):271-6. 
4. Zhou YL, Chen G, Bi DC, Chen X. Short-term Clinical Efficacy of Percutaneous Transforaminal Endoscopic Discectomy in Treating Young Patients With Lumbar Disc Herniation. J Orthop Surg Res. 2018;20;13(1):61.

5. Tu ZM, Li YW, Wang B, Lu GH, Li L, Lei k, et al. Clinical outcome of fullendoscopic interlaminar discectomy for single-level lumbar disc herniation: a minimum of 5-year follow-up. Pain Physician. 2017;20(3):E425-30.

6. Ahn SS, Chin DK, Kim SH, Kim DW, Lee BH, Ku MG. The clinical significance of lumbosacral transitional vertebrae on the surgical outcomes of lumbar discectomy: a retrospective cohort study of young adults. World Neurosurg. 2017;99:745-50.

7. Dong Q, Ren GX, Zhang KQ, Liu DY, Dou QL, Hao DJ. Genetic Polymorphisms of ALDH2 Are Associated With Lumbar Disc Herniation in a Chinese Han Population. Sci Rep. 2018;30;8(1):13079.

8. Brailsford JF. Deformities of the lumbosacral region of the spine. Br J Surg.2005;16(64):562-627.

9. Farfan HF, Sullivan JD. The relation of facet orientation to intervertebral disc failure. Can J Surg.1967;10(2):179-85.

10. Ishihara $H$, Matsui $H$, Osada $R$, Ohshima $H$, Tsuji $H$. Facet joint asymmetry as a radiologic feature of lumbar intervertebral disc herniation in children and adolescents. Spine. 1997;22(17):2001-4.

11. Asano S, Kaneda K, Umechara S, Tadano S. The mechanical properties of the human L4-5 functional spinal unit during cyclic loading. The structural efects of the posterior elements. Spine. 1992; 17(11):1343-52.

12. Ghosh S, Chaudhary V. Supervised methods for detection and segmentation of tissues in clinical lumbar MRI. Comput Med Imaging Graph. 2014;38(7):639-49.

13. Lurie JD, Tosteson AN, Tosteson TD, Carragee E, Carrino JA, Kaiser J, et al. Reliability of magnetic resonance imaging readings for lumbar disc herniation in the Spine Patient Outcomes Research Trial (SPORT). Spine. 2008;33(9):991-8.

14. Tao SW, Jin L, Hou ZY, Zhang Wei, Chen Tao, Zhang Yingze. A New Radiographic Feature of Lower Lumbar Disc Herniation in Young Patients. Int Orthop. 2018;42(3):583-6.

15. Andersson, GB. Epidemiology of low back pain. Acta Orthop Scand Suppl. 1998;281:28-31.

16. Battié MC, Videman T, Levälahti E, Gill K, Kaprio J. Genetic and Environmental Effects on Disc Degeneration by Phenotype and Spinal Level: A Multivariate Twin Study. Spine. 2008;33(25):2801-8.

17. Anderson GB. The biomechanics of the posterior elements of the lumbar spine. Spine. 1983;8(3):236.

18. King Al, Prasad P, Ewing CL. Mechanism of spinal injury due to candocephalad acceleration. Orthop Clin North Am. 1975;6(1):19-31.

19. Yang KH, King Al. Mechanism of facet load transmission as a hypothesis for low-back pain. Spine. 1984;9(6):557-65.

20. Bisschop A, Dieën JH, Kingma I, Veen AJ, Jiya TU, Mullender MG, et al. Torsion Biomechanics of the Spine Following Lumbar Laminectomy: A Human Cadaver Study. Eur Spine J. 2013;22(8):1785-93. 
21. Bisschop A, Mullender MG, Kingma I, Jiya TU, Veen AJ, Roos JC, et al. The impact of bone mineral density and disc degeneration on shear strength and stiffness of the lumbar spine following laminectomy. Eur Spine J. 2012;21(3):530-6.

22. Bisschop A, Royen BJ, Mullender MG, Paul CP, Kingma I, Jiya TU, et al. Which factors prognosticate spinal instability following lumbar laminectomy? Eur Spine J. 2012;21(12):2640-8.

23. Rao RD, Wang M, Singhal P, McGrady LM, Rao S. Intradiscal Pressure and Kinematic Behavior of Lumbar Spine After Bilateral Laminotomy and Laminectomy. Spine J. 2002;2(5):320-6.

24. Cunningham BW, Kotani Y, McNulty PS, Cappuccino A, McAfee PC. The effect of spinal destabilization and instrumentation on lumbar intradiscal pressure. Spine. 1997;22(22):2655-63.

25. Holm S, Nachemson A. Variations in the nutrition of the canine intervertebral disc induced by motion. Spine. 1983;8(8):866-74.

26. Hutton WC, Toriatake Y, Elmer WA, Ganey TM, Tomita K, Whitesides TE. The effect of compressive force applied to the intervertebral disc in vivo: a study of proteoglycans and collagen. Spine. 1998; 23(23):2524-37.

27. Lotz JC, Chin JR. Intervertebral disc cell death is dependent on the magnitude and duration of spinal loading. Spine. 2000; 25(12):1477-83.

28. Okuda S, Oda T, Miyauchi A, Tamura S, Hashimoto Y, Yamasaki S, et al. Lamina horizontalization and facet tropism as the risk factors for adjacent segment degeneration after PLIF. Spine. 2008;33(25):2754-8.

29. Gregerson DM. Clinical consequences of spina bifida occulta. J Manipulative Physiol Ther. 1997;20(8):546-50.

30. Taskaynatan MA, İzci Y, Ozgul A, Hazneci B, Dursun H, Kalyon TA. Clinical Significance of Congenital Lumbosacral Malformations in Young Male Population With Prolonged Low Back Pain. Spine. 2005;30(8):E210-3.

31. Herkowitz HN, Kurz LT. Degenerative lumbar spondylolisthesis with spinal stenosis. A prospective study comparing decompression with decompression and intertransverse process arthrodesis. $J$ Bone Joint Surg Am.1991;73(6):802-8.

32. Battié MC, Videman T, Parent E. Lumbar disc degeneration: epidemiology and genetic influences. Spine. 2004; 29(23):2679-90.

33. Manninen $P$, Riihimäk $H$, Heliövaara $M$. Incidence and riskfactors of low-back pain in middle-aged farmers. Occup Med(Lond). 1995;45(3):141-6.

34. Riihimäki H, Wickström G, Hänninen K, Luopajärvi T. Predictors of sciatic pain among concrete reinforcement workers and house painters-a five-year follow-up. Scand J Work Environ Health. 1989;15(6):415-23.

35. Lener S, Wipplinger C, Hartmann S, Thomé C, Tschugg A. The Impact of Obesity and Smoking on Young Individuals Suffering From Lumbar Disc Herniation: A Retrospective Analysis of 97 Cases. Neurosurg Rev. 2019; doi: 10.1007/s10143-019-01151-y. 
36. Martinez NG, Orribo LP, Kalb S, Reyes PM, Newcomb AG, Hughes J, et al. The Role of Obesity in the Biomechanics and Radiological Changes of the Spine: An in Vitro Study. J Neurosurg Spine. 2016;24(4):615-23.

37. Heuer $F$, Schmidt $H$, Wilke HJ. Stepwise reduction of functional spinal structures increase disc bulge and surface strains. J Biomech. 2008;41(9):1953-60.

38. Aihara T, Takahashi K, Ono Y, Moriya H. Does the morphology of the iliolumbar ligament affect lumbosacral disc degeneration. Spine. 2002; 27(14):1499-503.

\section{Figures}

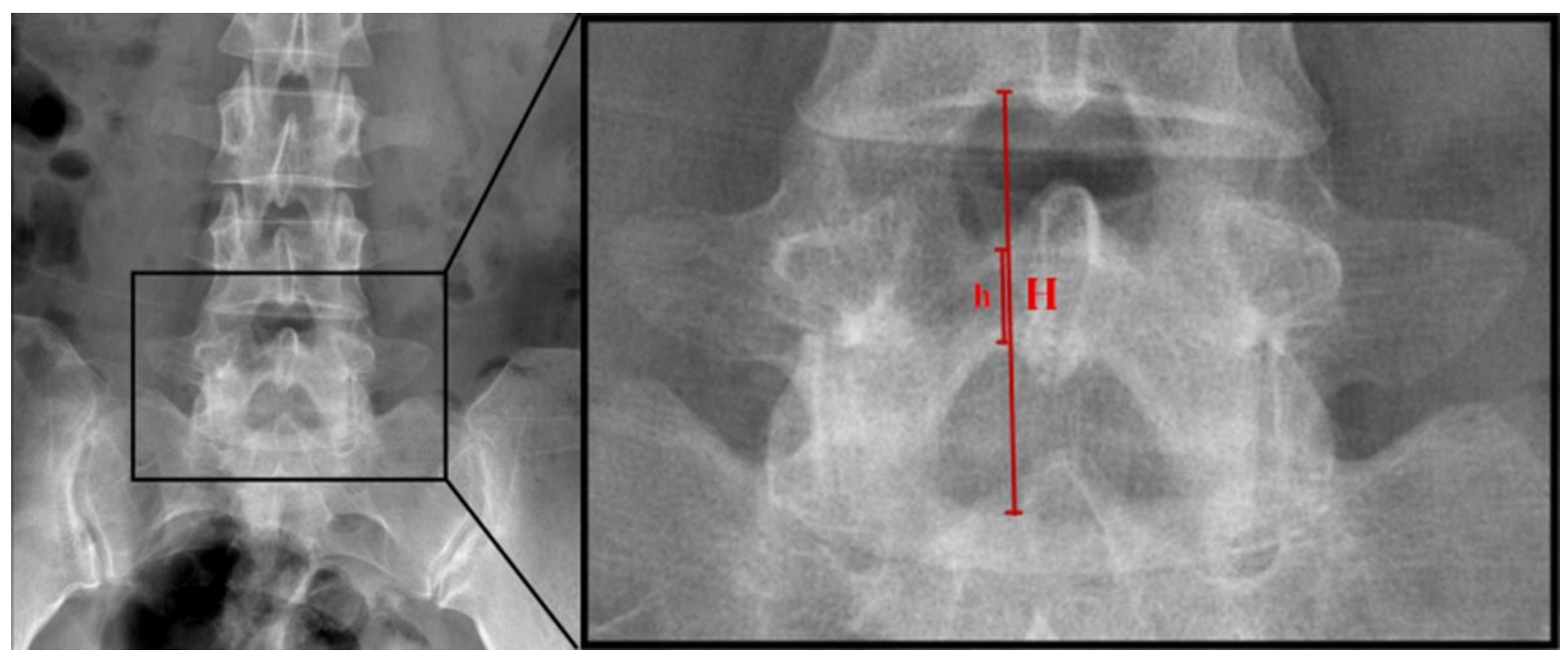

Figure 1

On the anteroposterior $\mathrm{X}$-ray of lumbar spine, the ratio of " $\mathrm{h} / \mathrm{H}$ " was measured and calculated.

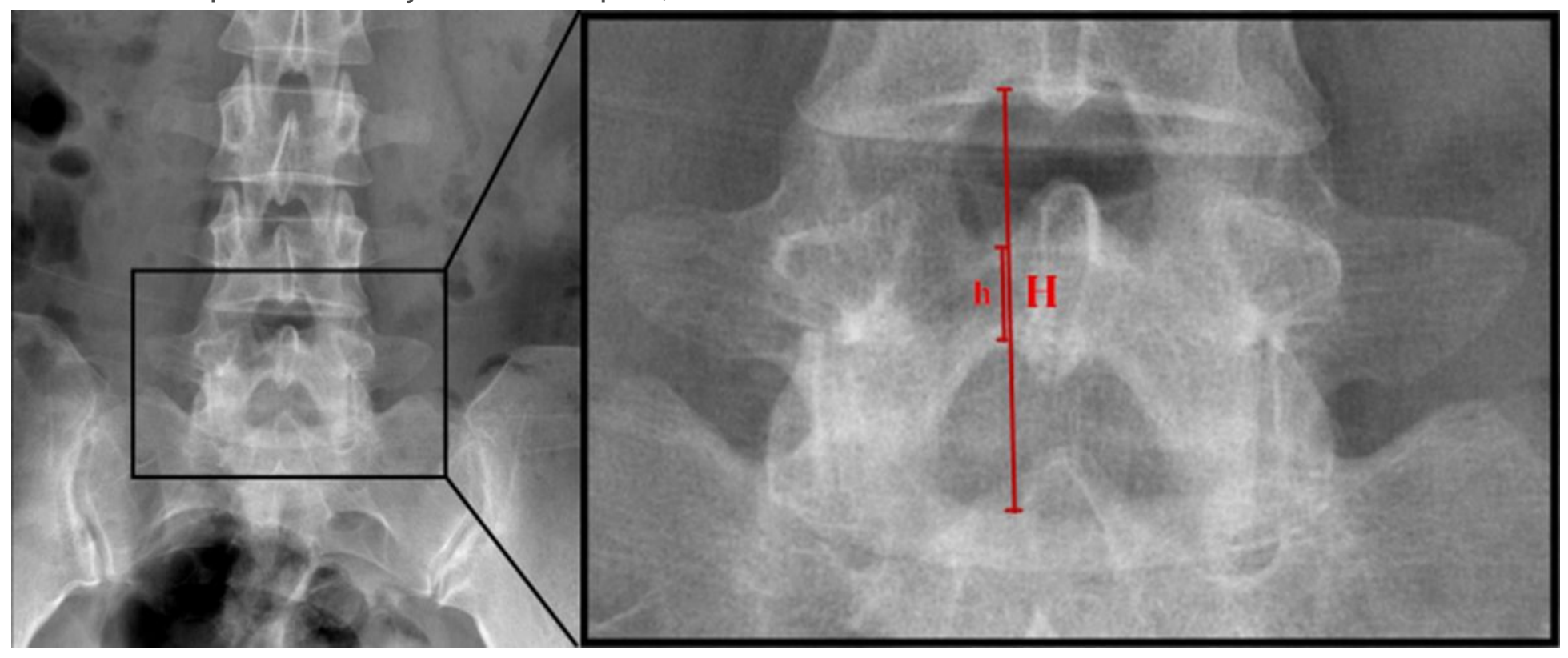




\section{Figure 1}

On the anteroposterior X-ray of lumbar spine, the ratio of " $\mathrm{h} / \mathrm{H}$ " was measured and calculated.

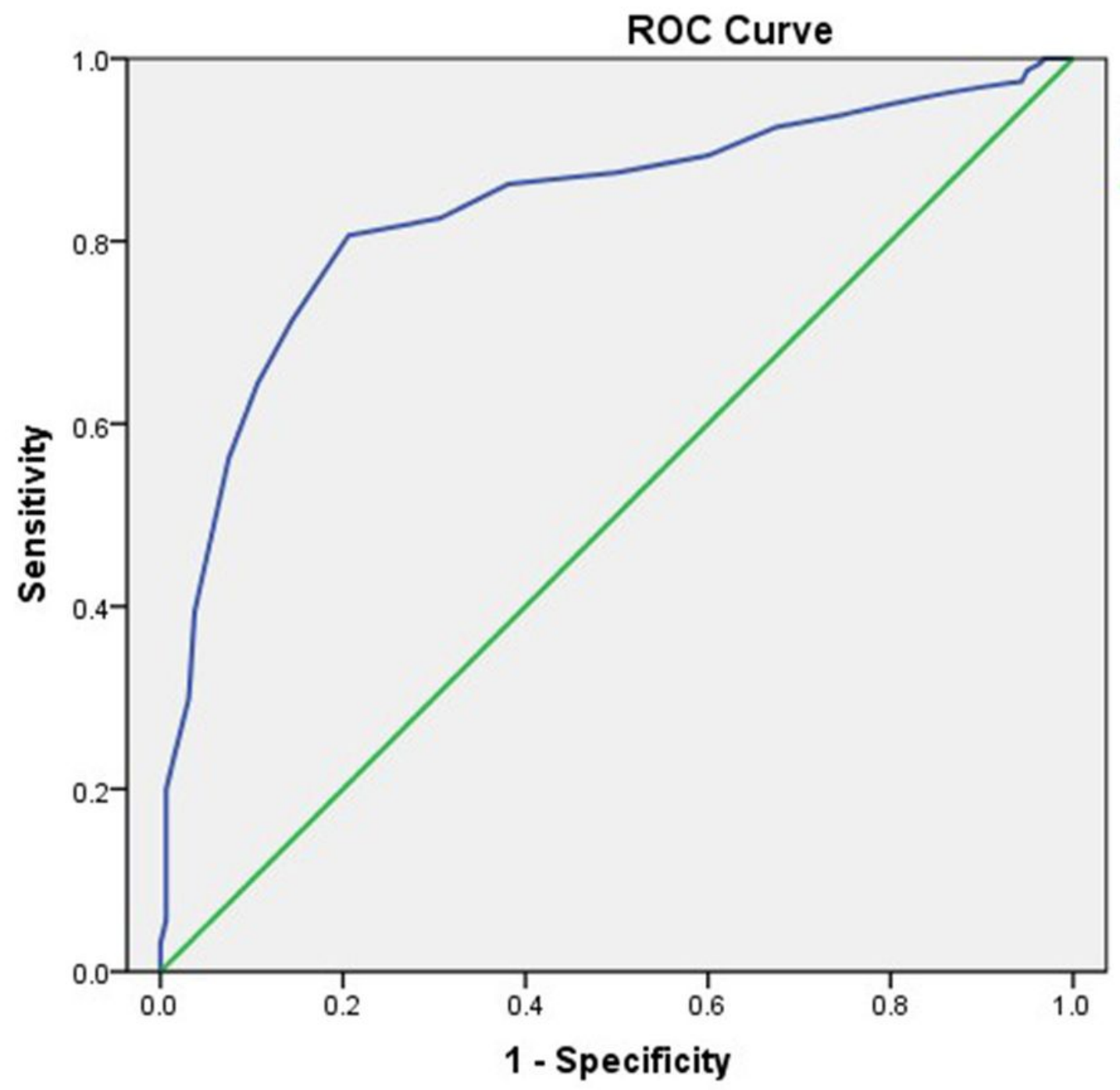

Source of the Curve — the rate of " $h / H$ " - reference line

Figure 2

ROC curve of the rate of " $h / H^{\prime}$. 


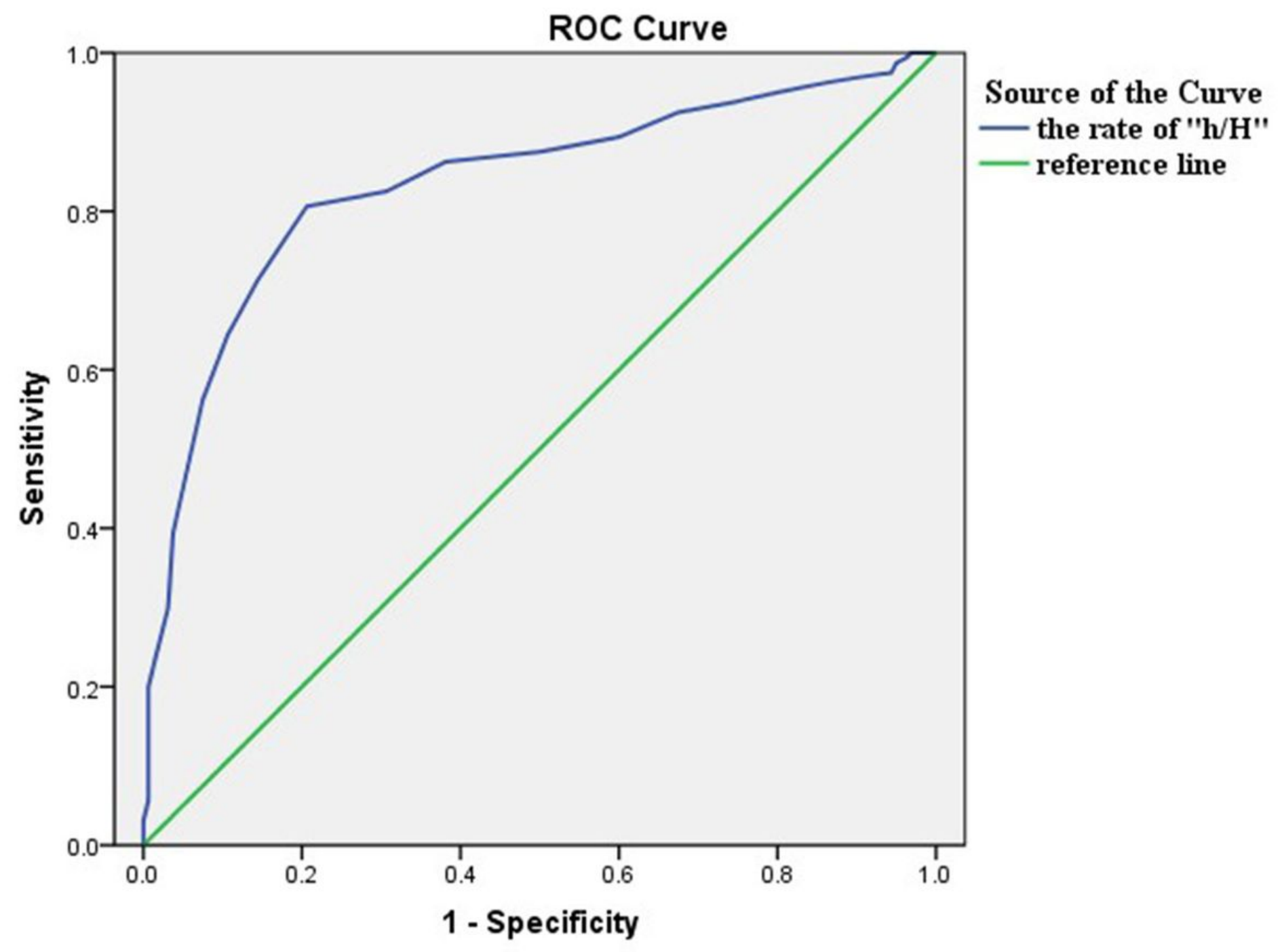

Figure 2

ROC curve of the rate of " $h / H$ ". 